\title{
SISTEM PEMINJAMAN BARANG INVENTARIS MEDIA PERKULIAHAN BERBASIS QRCODE SEBAGAI PENDAMPING SISTEM KONVENSIONAL UNTUK PENGELOLAAN BARANG
}

\author{
Agus Setiawan'), Zaenuddin ${ }^{2)}$ \\ ${ }^{\mathbf{1}}$ Fakultas Teknologi Informasi, Universitas Islam Kalimantan Muhammad Arsyad Al Banjari Banjarmasin \\ email : agusteknik08@gmail.com \\ ${ }^{2}$ Fakultas Teknologi Informasi, Universitas Islam Kalimantan Muhammad Arsyad Al Banjari Banjarmasin \\ email : zaenuddin.uniska@gmail.com
}

\begin{abstract}
ABSTRAK
Fasilitas yang disediakan oleh UNISKA atau Fakultas Teknologi Informasi harus menyesuaikan jumlah mahasiswa. Sebagian kelas memang telah terpasang alat media perkuliahan seperti LCD/LED televisi, tapi masih ada kelas atau ruangan yang belum ada fasilitas tersebut. Sebagai pengganti LEC/LCD maka fakultas menyediakan proyektor, kabel hdmi, kabel vga dan stop kontak. Permasalahan yang terjadi adalah pihak fakultas tidak bisa memonitoring jika terjadi kehilangan barang inventaris tersebut. Sistem yang sedang berjalan adalah penggunaan pencatatan biasa media kertas yang ditulis manual dengan variabel nama peminjam, alat yang dipinjam atau dibawa, semester berapa yang meminjam. Berdasarkan sistem tersebut permasalahan yang terjadi adalah sering hilangnya barang yang tidak dikembalikan khususnya kabel hdmi, vga, dan colokan kabel karena belum ada sistem yang khusus untuk memonitoring barang yang telah dipinjam. Maka dari itu perlunya suatu sistem yang mengelola sistem peminjaman alat media perkuliahan yang kemudian semua alat inventaris akan dibuatkan identitas qrcodenya masing-masing sehingga mudah untuk pendataan barang. Pihka peminjam akan mengisi nama ketua kelas yang bertanggung jawab, kemudian menginput durasi atau lama waktu peminjaman alat tersebut. Jika dalam durasi tersebut barang belum dikembalikan maka akan keluar notif agar barang tersebut segera dikembalikan.
\end{abstract}

Kata Kunci : barang, inventaris, peminjaman, pengembalian, qrcode

\section{PENDAhuluan}

Sistem berasal dari bahasa Latin (systēma) dan bahasa Yunani (sustēma) adalah suatu kesatuan yang terdiri komponen atau elemen yang dihubungkan bersama untuk memudahkan aliran informasi, materi atau energi untuk mencapai suatu tujuan. Istilah ini sering dipergunakan untuk menggambarkan suatu set entitas yang berinteraksi, di mana suatu model matematika seringkali bisa dibuat. (https://id.wikipedia.org/wiki/Sistem diakses tgl 19 September 2018).

Fakultas Teknologi Informasi merupakan salah satu fakultas dari UNISKA MAB Banjarmasin yang terbanyak jumlah mahasiswanya. Fasilitas yang disediakan oleh yayasan universitas harus menyesuaikan jumlah mahasiswa. Sebagian kelas memang telah terpasang alat media perkuliahan seperti LCD/LED televisi, tapi masih ada kelas atau ruangan yang belum ada fasilitas tersebut. Sebagai pengganti LED/LCD maka fakultas menyediakan proyektor, kabel hdmi, kabel vga dan stop kontak.

Permasalahan yang terjadi adalah pihak fakultas tidak bisa memonitoring jika terjadi kehilangan barang inventaris tersebut. Sistem yang sedang berjalan adalah penggunaan pencatatan biasa media kertas yang ditulis manual dengan variabel nama peminjam, alat yang dipinjam atau dibawa, semester berapa yang meminjam. Berdasarkan sistem tersebut permasalahan yang terjadi adalah sering hilangnya barang yang tidak dikembalikan khususnya kabel hdmi, vga, dan colokan kabel karena belum ada sistem yang khusus untuk memonitoring barang yang telah dipinjam. 
Maka dari itu perlunya suatu sistem yang mengelola sistem peminjaman alat media perkuliahan yang kemudian semua alat inventaris akan dibuatkan identitas qrcodenya masing-masing sehingga mudah untuk pendataan barang. Pihka peminjam akan mengisi nama ketua kelas yang bertanggung jawab, kemudian menginput durasi atau lama waktu peminjaman alat tersebut. Jika dalam durasi tersebut barang belum dikembalikan maka akan keluar notif agar barang tersebut segera dikembalikan..

\section{METODE PENELITIAN}

Penelitian ini menggunakan istilah Research and Development adalah metode yang digunakan untuk menghasilkan produk tertentu dan menguji daripada keefektifan produk tersebut bagi pengguna. Pendekatan model perangkat lunak untuk mendukung penelitian ini menggunakan model waterfall, yang melalui beberapa tahapan, yaitu seperti pada gambar dibawah ini:

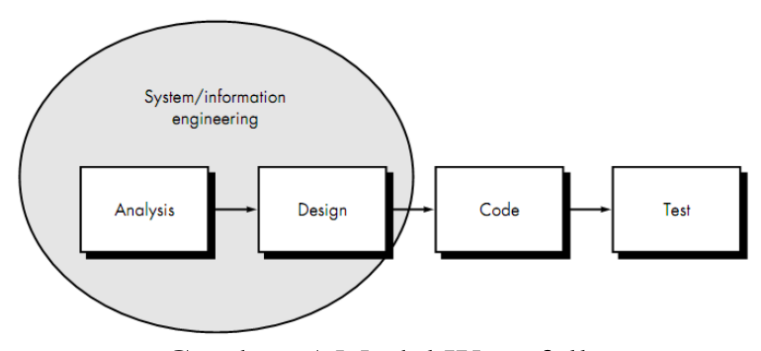

Gambar 1 Model Waterfall

1. Tahap analisis

2. Tahap desain

3. Tahap implementasi / coding

4. Tahap testing sistem

5. Tahap Pengujian

\section{HASIL DAN PEMBAHASAN}

a. Analisis

Pada tahap ini tim melakukan observasi dan wawancara langsung dengan objek penelitian

\section{b. Tahap Desain}

Pada tahap ini didesain dengan menggunakan diagram konteks sebagai awal alur dari sebuah sistem/aplikasi. Untuk perancangan desain antarmuka menggunakan tools Balsamic Mockup.

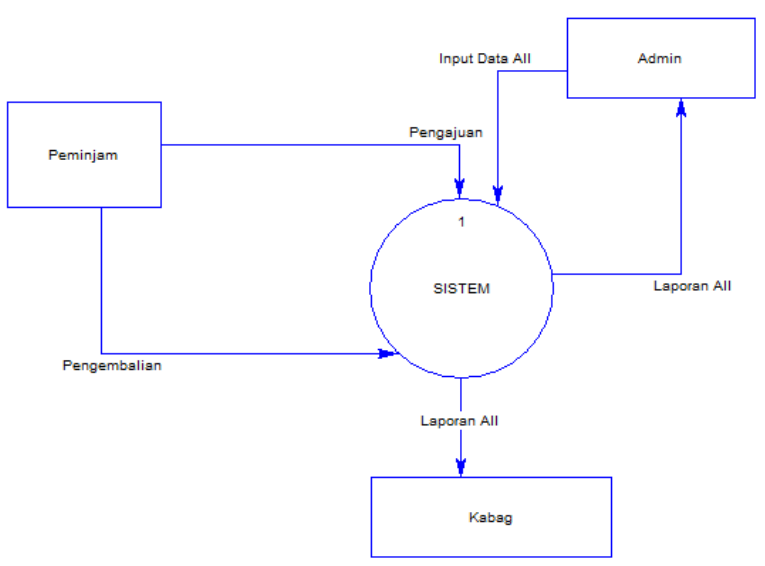

Gambar 2 Diagram Konteks

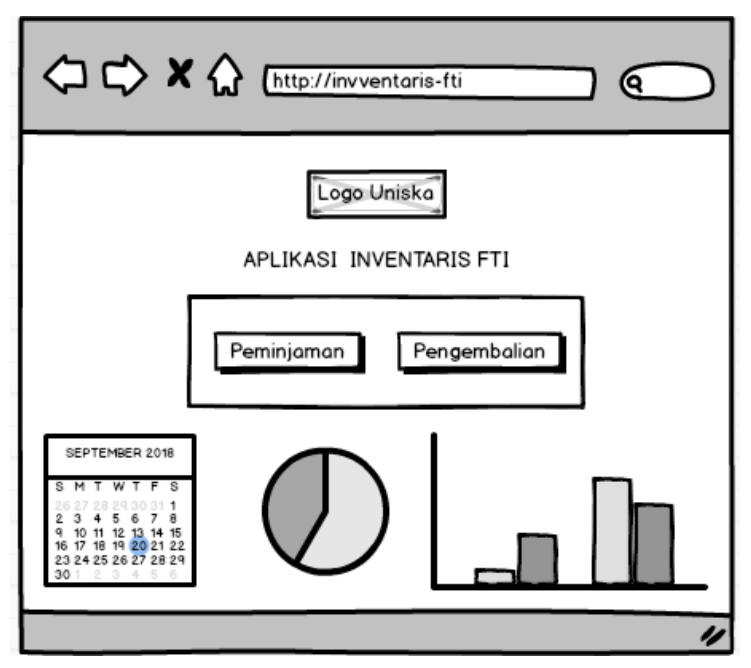

Gambar 3 Desain Mockup index 


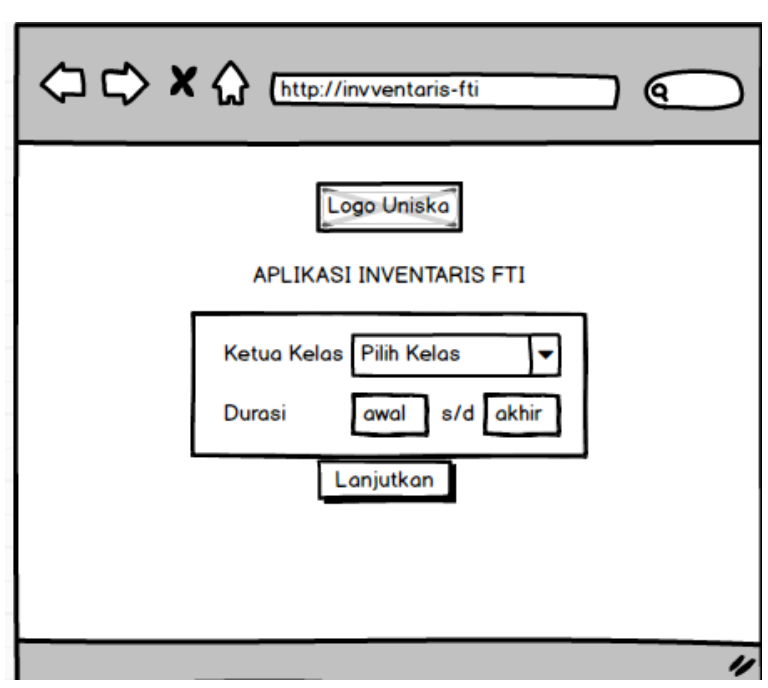

Gambar 4 Desain halaman ketua kelas

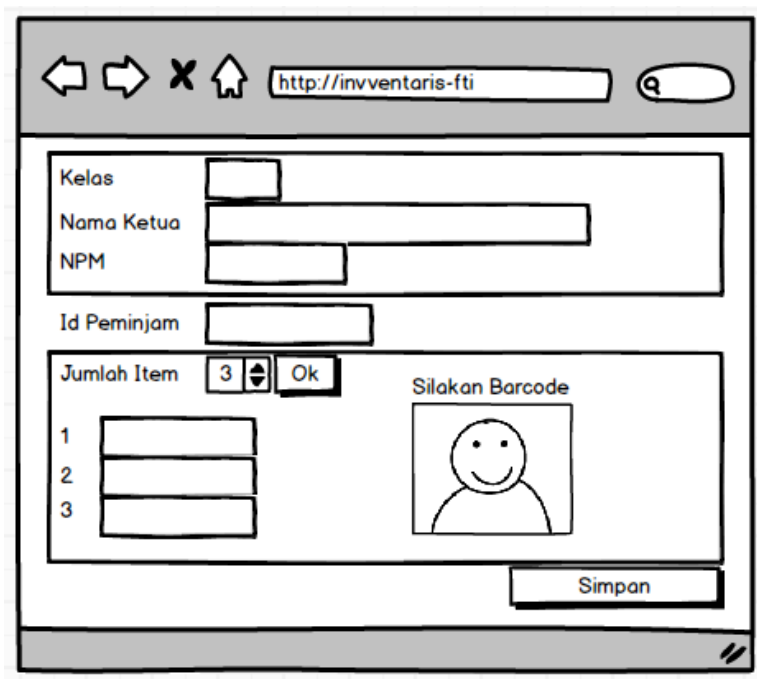

Gambar 5 Desain halaman peminjaman

c. Tahap Implementasi

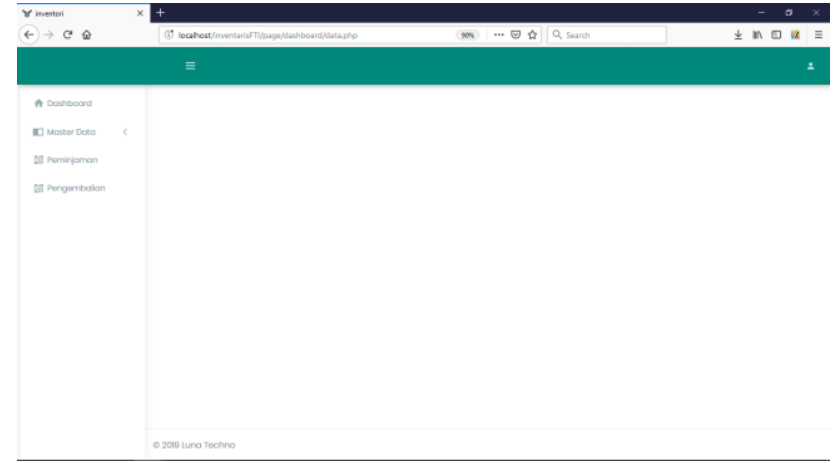

Gambar 7 Home Admin

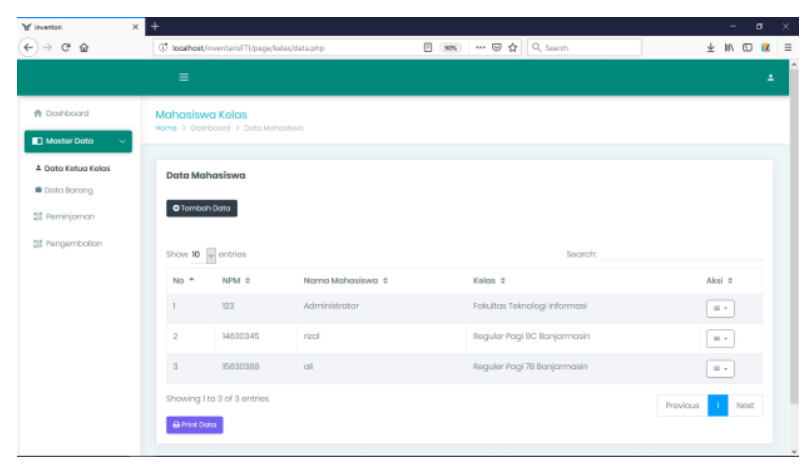

Gambar 8 input data ketua kelas

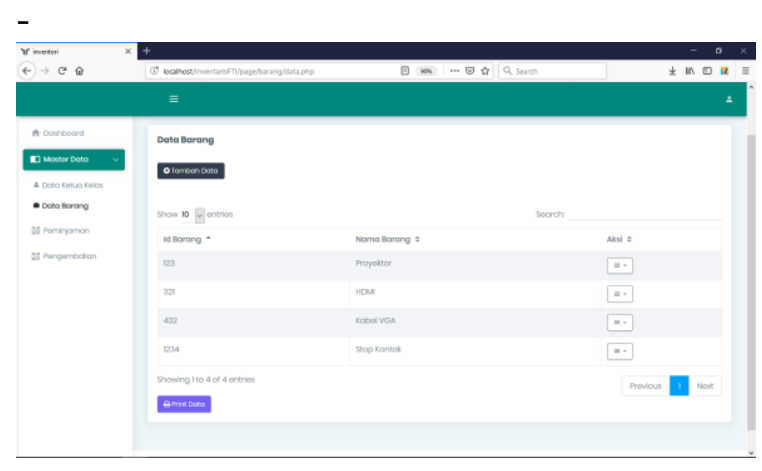

Gambar 9 input data barang inventaris 


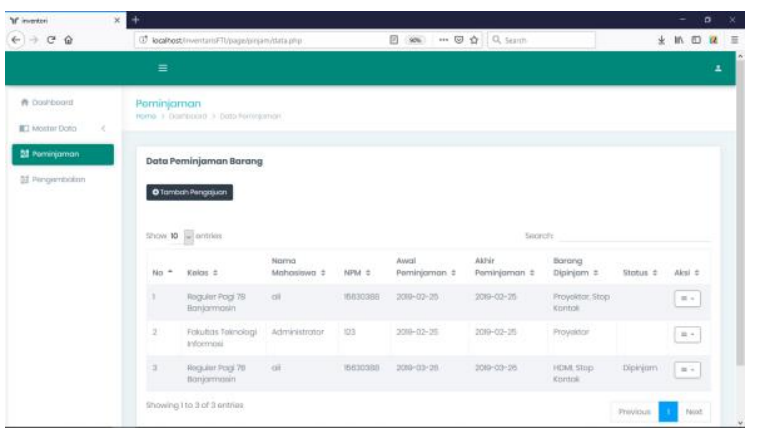

Gambar 10 data peminjaman

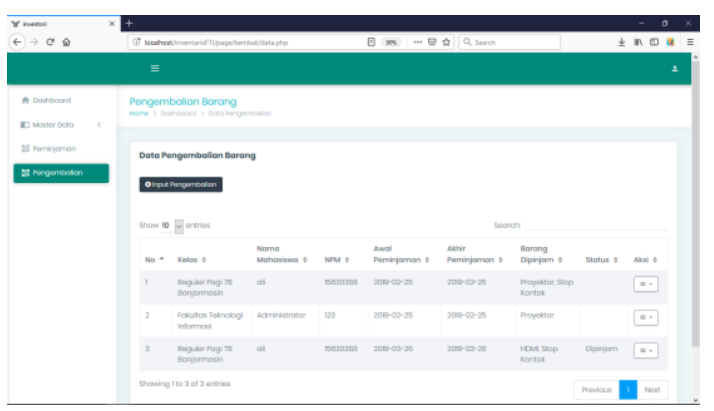

Gambar 11 data pengembalian

\section{d. Tahap Pengujian}

Pada tahap ini pengujian dilakukan dengan mengundang Responden sebanyak 10 Orang

Tabel 1 Pengujian Usability

\begin{tabular}{llllll} 
No & Pertanyaan & KS & S & SS \\
\hline 1 & $\begin{array}{l}\text { Secara keseluruhan } \\
\text { saya puas dengan } \\
\text { kemudahan pemakaian } \\
\text { aplikasi ini }\end{array}$ & 0 & 0 & 8 & 2 \\
\hline 2 & $\begin{array}{l}\text { Sangat sederhana } \\
\text { penggunaan aplikasi } \\
\text { ini }\end{array}$ & 0 & 0 & 0 & 10 \\
\hline $\begin{array}{l}\text { Saya dapat dengan } \\
\text { sempurna } \\
\text { menyelesaikan } \\
\text { pekerjaan dengan } \\
\text { aplikasi ini }\end{array}$ & 0 & 0 & 2 & 8 \\
\hline $\begin{array}{l}\text { Saya dapat } \\
\text { menyelesaikan } \\
\text { pekerjaan saya dengan } \\
\text { cepat menggunakan } \\
\text { aplikasi ini }\end{array}$ & 0 & 0 & 5 & 5 \\
\hline
\end{tabular}

Saya dapat

menyelesaikan

5 pekerjaan saya secara $\quad \begin{array}{lllll}0 & 0 & 5 & 5\end{array}$ efisien menggunakan aplikasi ini

Saya merasa nyaman

6 menggunakan aplikasi $\quad \begin{array}{llll}0 & 0 & 5 & 5\end{array}$ ini

Sangat mudah

7 mempelajari

$\begin{array}{lllll}\text { penggunaan aplikasi } & 0 & 0 & 4 & 6\end{array}$

ini

Pesan kesalahan yang

diberikan aplikasi ini

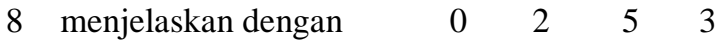

gamblang cara

mengatasinya

Kapanpun saya

membuat kesalahan,

9 saya bisa

memperbaikinya

dengan cepat dan

mudah

Informasi yang

10 disediakan aplikasi ini $\quad \begin{array}{lllll}0 & 0 & 0 & 10\end{array}$ cukup jelas

Sangat mudah mencari

11 informasi di aplikasi $\quad \begin{array}{lllll}0 & 0 & 7 & 3\end{array}$ ini

Informasi yang

12 disediakan aplikasi $\quad \begin{array}{lllll}0 & 0 & 0 & 10\end{array}$

sangat mudah

dipahami

Informasi yang

13 disediakan efektif

membantu saya mendapatkan informasi

Pengorganisasian

14 informasi yang

$\begin{array}{lllll}\text { ditampilkan aplikasi } & 0 & 0 & 10 & 0\end{array}$

sangat jelas $15 \begin{array}{lllll}\begin{array}{l}\text { Antarmuka aplikasi } \\ \text { menyenangkan }\end{array} & 0 & 0 & 10 & 0\end{array}$

Saya menyukai

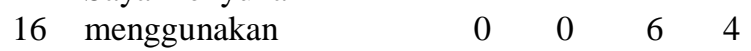
antarmuka aplikasi ini

Aplikasi ini memiliki

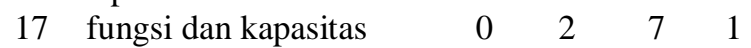
sesuai harapan saya

Secara keseluruhan,

18 saya puas dengan $\quad \begin{array}{lllll}0 & 0 & 10 & 0\end{array}$

aplikasi ini

Apakah informasi yang

19 disediakan oleh

aplikasi ini mudah

$\begin{array}{llll}0 & 0 & 10 & 0\end{array}$ dimengerti 


\begin{tabular}{|c|c|c|c|c|c|}
\hline 20 & $\begin{array}{l}\text { Apakah penggunakan } \\
\text { menu atau fitur } \\
\text { aplikasi menu mudah } \\
\text { digunakan }\end{array}$ & 0 & 0 & 10 & 0 \\
\hline 21 & $\begin{array}{l}\text { Apakah aplikasi ini } \\
\text { nyaman digunakan }\end{array}$ & 0 & 0 & 10 & 0 \\
\hline 22 & $\begin{array}{l}\text { Apakah aplikasi ini } \\
\text { sesuai dengan } \\
\text { kebutuhan }\end{array}$ & 0 & 0 & 9 & 1 \\
\hline 23 & $\begin{array}{l}\text { Apakah aplikasi ini } \\
\text { dapat dengan mudah } \\
\text { dipelajari }\end{array}$ & 0 & 0 & 10 & 0 \\
\hline 24 & $\begin{array}{l}\text { Apakah aplikasi ini } \\
\text { mudah dioperasikan }\end{array}$ & 0 & 0 & 10 & 0 \\
\hline 25 & $\begin{array}{l}\text { Apakah aplikasi } \\
\text { bermanfaat bagi } \\
\text { pengguna }\end{array}$ & 0 & 0 & 8 & 2 \\
\hline 26 & $\begin{array}{l}\text { Apakah tampilan menu } \\
\text { dalam aplikasi mudah } \\
\text { untuk dikenali }\end{array}$ & 0 & 0 & 10 & 0 \\
\hline 27 & $\begin{array}{l}\text { Apakah aplikasi } \\
\text { mempunyai } \\
\text { kemampuan dan fungsi } \\
\text { sesuai yang diharapkan }\end{array}$ & 0 & 0 & 10 & 0 \\
\hline & Total & 0 & 4 & 189 & 77 \\
\hline
\end{tabular}

Hasil pengujian Usability

\begin{tabular}{crcc}
\hline Tidak Setuju & 0 & $\times 100 \%$ & $0 \%$ \\
\hline Kurang Setuju & 0,01 & $\times 100 \%$ & $1 \%$ \\
\hline Setuju & 0,7 & $\times 100 \%$ & $70 \%$ \\
\hline Sangat Setuju & 0,29 & $\times 100 \%$ & $29 \%$ \\
\hline
\end{tabular}

Berdasarkan analisis deskriptif dan perhitungan maka diperoleh persentase $29 \%$ Sangat setuju, $70 \%$ setuju, $1 \%$ kurang setuju, dan $0 \%$ untuk respon tidak setuju.

Analisis Pengujian

Tabel 2 Analisis Pengujian

\begin{tabular}{cccr}
\hline $\begin{array}{c}\text { Pertan } \\
\text { yaan }\end{array}$ & $\begin{array}{c}\text { Skor } \\
\text { Total }\end{array}$ & $\begin{array}{c}\text { Skor } \\
\text { Maksimum }\end{array}$ & \multicolumn{1}{c}{$\%$} \\
\hline 1 & 32 & 40 & 80 \\
\hline 2 & 40 & 40 & 100 \\
\hline 3 & 38 & 40 & 95 \\
\hline 4 & 35 & 40 & 87,5 \\
\hline 5 & 35 & 40 & 87,5 \\
\hline 6 & 35 & 40 & 87,5 \\
\hline
\end{tabular}

\begin{tabular}{|c|c|c|c|}
\hline 7 & 36 & 40 & 90 \\
\hline 8 & 27 & 40 & 67,5 \\
\hline 9 & 31 & 40 & 77,5 \\
\hline 10 & 40 & 40 & 100 \\
\hline 11 & 33 & 40 & 82,5 \\
\hline 12 & 40 & 40 & 100 \\
\hline 13 & 31 & 40 & 77,5 \\
\hline 14 & 30 & 40 & 75 \\
\hline 15 & 30 & 40 & 75 \\
\hline 16 & 34 & 40 & 85 \\
\hline 17 & 25 & 40 & 62,5 \\
\hline 18 & 30 & 40 & 75 \\
\hline 19 & 30 & 40 & 75 \\
\hline 20 & 30 & 40 & 75 \\
\hline 21 & 30 & 40 & 75 \\
\hline 22 & 31 & 40 & 77,5 \\
\hline 23 & 30 & 40 & 75 \\
\hline 24 & 30 & 40 & 75 \\
\hline 25 & 32 & 40 & 80 \\
\hline 26 & 30 & 40 & 75 \\
\hline 27 & 30 & 40 & 75 \\
\hline Total & 875 & 1080 & 81 \\
\hline
\end{tabular}

Berdasarkan hasil analisa pengujian usability maka diperoleh presentase $81 \%$. Dari skor tersebut untuk aplikasi yang sederhana termasuk dalam kategori baik.

\section{KESIMPULAN}

Kesimpulan yang didapatkan setelah melakukan implementasi dan beberapa pengujiian, maka dapat dipaparkan yaitu: Tahap pengujian usability hasil analisa pengujian maka diperoleh presentase $81 \%$. Dari skor tersebut untuk aplikasi yang sederhana termasuk dalam kategori baik.

\section{REFERENSI}

1] F. Nugraha, "Analisa dan Perancangan Sistem Informasi Perpustakaan," J. SIMETRIS, 2014.

2] H. W. Luthfi and B. K. Riasti, "Sistem Informasi Perawatan Dan Inventaris 
Laboratorium Pada Smk Negeri 1

Rembang Berbasis Web," Indones. J.

Comput. Sci. - Speed, 2013

3] M. Rohayati, "MEMBANGUN

SISTEM INFORMASI

MONITORING DATA INVENTORY

DI VIO HOTEL INDONESIA," $J$.

Ilm. Komput. dan Inform., 2014

4] A. Riyandwyana, E. S. Mukhlason, J.

S. Informasi, and F. T. Informasi,

"Pengembangan Sistem Rekomendasi

Peminjaman Buku Berbasis Web

Menggunakan Metode Self Organizing

Map Clustering Pada Badan

Perpustakaan Dan Kearsipan

(BAPERSIP) Provinsi Jawa Timur," $J$.

Tek. ITS, 2013.

5] K. Firdausy, S. Samadri, and A. Y. Yudhana, "SISTEM INFORMASI

PERPUSTAKAAN BERBASIS WEB DENGAN PHP DAN MYSQL," TELKOMNIKA (Telecommunication Comput. Electron. Control., 2008.

6] A. P. M. A. Arif, Nur Saiful; Wanda, "Aplikasi Administrasi Perpustakaan Berbasis Web Smk Swasta Brigjend Katamso Medan," J. Ilm. Saintikom, 2013.

7] MARTIN, James. Information engineering: book II: planning and analysis. Prentice-Hall, Incorporated, 1989

8] A. P. M. A. Arif, Nur Saiful; Wanda, "Aplikasi Administrasi Perpustakaan Berbasis Web Smk Swasta Brigjend Katamso Medan," J. Ilm. Saintikom, 2013 